\title{
ESTUDO DE SECAGEM DE PÊRA BARTLETT (Pyrus sp.) EM FATIAS ${ }^{1}$
}

\author{
Kil Jin PARK ${ }^{2, *}$, Maurício Kenze Moreno YADO ${ }^{3}$, Fernando Pedro Reis BROD ${ }^{4}$
}

\begin{abstract}
RESUMO
O processo de secagem visa a redução do teor de água fazendo com que a atividade da água dos produtos in natura diminua drasticamente, aumentando o tempo de conservação e a vida útil do produto e facilitando seu transporte, manuseio e armazenamento. Através do uso de um secador convectivo vertical de bandejas, determinaram-se as curvas de secagem da pêra bartlett (Pyrus sp.) nas temperaturas de 50,60 e $70^{\circ} \mathrm{C}$ e velocidades do ar de $0,5,1,0$ e 1,5m/s, obtendo-se nove curvas de secagem. Através destas curvas o estudo da secagem foi conduzido avaliando as difusividades efetivas e as energias de ativação.

Palavras-chave: secador convectivo; difusividade efetiva; energia de ativação.

\section{SUMMARY}

DRYING STUDIES OF SLICED PEAR BARTLETT (Pyrus sp.). The drying process aims for the reduction of the in natura products water activity, increasing the shelf life and facilitating the transport, maintenance and storage. Using a convective vertical tray drier, we obtained the drying curves of pear (nine curves) at three different temperatures $\left(50,60\right.$ and $\left.70^{\circ} \mathrm{C}\right)$ and three different air velocities $(0.5,1.0$ and $1.5 \mathrm{~m} / \mathrm{s})$. With these results, it was possible to study the drying process determining the effective diffusivities and activation energies.
\end{abstract}

Keywords: convective dryer; effective diffusivity; activation energy.

\section{1 - INTRODUÇÃO}

A pereira é uma fruteira típica de clima temperado, tendo como origem a região asiática [10]. Botanicamente, a pereira pertence à família das Rosáceas (pomoídeas) e engloba dezenas de espécies do gênero Pyrus [6].

No contexto da produção mundial das frutíferas pomoídeas, as peras só perdem para as maçãs e são consumidas tanto ao natural quanto industrializadas: em calda, secas, em sucos ou vinhos finos (perry, ou cidra de peras). CAMPO-DALL'ORTO et al. [6] estimam a produção mundial de peras em aproximadamente dez milhões de toneladas por ano: a Europa produz cerca de cinco milhões de toneladas; a Ásia, dois milhões; a América do Norte, quase um milhão; a América do Sul, cerca de 500 mil; a Oceania e a África do Sul, em torno

\footnotetext{
${ }_{1}^{1}$ Recebido para publicação em 10/04/00. Aceito para publicação em 19/09/01.

2 Prof. Titular, Depto. Pré-Processamento de Produtos Agropecuários, Faculdade de Engenharia Agrícola, UNICAMP, Caixa Postal 6011, Campinas - SP, CEP: 13081-970. Tel: (0xx19) 788-1076, e-mail:kil@agr.unicamp.br.

${ }^{3}$ Engenheiro de Alimentos, FEA/UNICAMP, Campinas, SP.

${ }^{4}$ Doutorando em Engenharia Agrícola, FEAGRI/UNICAMP, Campinas, SP, e-mail: brod@agr.unicamp.br.

${ }^{*}$ A quem a correspondência deve ser enviada.
}

de 250 mil toneladas cada um. Na Europa os países maiores produtores são a Itália (1/3 do total), a Alemanha e a França.

Espera-se que, com o aumento da população brasileira e a melhoria do seu poder aquisitivo, haja a elevação do consumo dessa fruta. A produção brasileira, ao redor de 50 mil toneladas por ano (sendo Santa Catarina o maior Estado produtor) e de qualidade inferior, a curto prazo, não atenderá essa demanda e não impedirá os gastos superiores a 50 milhões de dólares na importação de peras, até mesmo pela dificuldade climática encontrada no país [6].

O processamento de peras é comum em alguns países, como os EUA, ao contrário do que ocorre no Brasil, uma vez que a produção não é significativa. As técnicas de processamento mais comuns são: conservas em calda, purês para uso em néctares, iogurtes e secagem [10]. A secagem é um processo que pode ser utilizado para vários fins, como em produtos de panificação, molhos e compotas e para consumo da própria fruta seca [7].

A secagem de peras nos EUA é uma prática antiga que data do começo do século. A primeira técnica usada para secagem de peras foi também a mais antiga técnica para secagem de frutas: a secagem pelo sol, que era usada por persas, gregos e egípcios desde os tempos bíblicos. De acordo com McBEAN [13], as peras secas desta forma são translúcidas de coloração amarelo pálido. A desidratação de peras utilizando secadores convectivos, apesar de ter sido bem sucedida não foi bem aceita, na prática, pelos consumidores americanos devido ao aspecto diferente das peras secas pelo sol, que possuíam o aspecto ao qual eles estavam habituados. Essas peras desidratadas, às vezes, eram brancas e opacas e não agradaram ao consumidor [13].

No Brasil, de acordo com CAMPO-DALL'ORTO et al. [6], o mercado de peras secas é muito pequeno e devido ao fato do consumidor não estar habituado ao produto, pode-se desenvolver técnicas de desidratação de peras possibilitando que tais produtos, de qualidade melhor que as peras secas pelo sol, sejam comercializados sem nenhum preconceito por parte do consumidor. Na região Sul do país, o chá de pêra é comum e após fazer o chá, a pêra reidratada é consumida polviIhada com açúcar.

As vantagens de se utilizar o processo de secagem são várias, dentre as quais tem-se: a facilidade na conservação do produto; estabilidade dos componentes aromáticos à temperatura ambiente por longos períodos de tempo; proteção contra degradação enzimática e oxidativa; redução do seu peso; economia de energia 
por não necessitar de refrigeração e a disponibilidade do produto durante qualquer época do ano. Assim, este trabalho tem como objetivo a obtenção da pêra seca.

A secagem é a eliminação da água do material através da evaporação. Existem dois métodos de secagem: a natural, feita pelo sol ou vento (método mais antigo); e a artificial, a qual necessita de fornecimento de energia, diferente da solar.

Durante a secagem é necessário o fornecimento de calor para evaporar a umidade do material e também deve haver um sorvedor de umidade para remover o vapor de água, formado na superfície do material a ser seco.

Ao ser colocado no secador, devido à diferença de temperatura (ambiente mais quente que material) ocorre uma transferência de calor da fonte quente para o material úmido, e também a evaporação da água. A diferença de pressão parcial de vapor d'água entre o ambiente quente (ar quente) e a superfície do produto ocasionará uma transferência de massa do produto para o ar, e assim o vapor será arrastado do material.

Se a água não estiver ligada (ligação física e/ou química) nas estruturas dos sólidos é caracterizada como água livre, e a energia envolvida no processo será correspondente ao calor latente de vaporização. $\mathrm{E}$, se a água estiver ligada, a energia necessária para sua evaporação será maior [3].

Durante a secagem, é na superfície do material que ocorre a evaporação da água, a qual foi transportada do interior do sólido. Os mecanismos desse transporte mais importantes são: difusão líquida, difusão de vapor e fluxo de líquido e de vapor.

O conhecimento do conteúdo inicial e final (equilíbrio) de umidade do material, da relação da água com a estrutura sólida e do transporte da água do interior do material até a sua superfície possibilitam fundamentar o fenômeno da secagem [3].

O fenômeno da secagem não pode ser generalizado para materiais biológicos, pois possuem características próprias e propriedades que podem sofrer importantes alterações durante a secagem.

As características específicas de cada produto, associadas às propriedades do ar de secagem e ao meio de transferência de calor adotado, determinam diversas condições de secagem. Entretanto, a transferência de calor e de massa entre o ar de secagem e o produto é fenômeno comum a qualquer condição de secagem. O processo de secagem, baseado na transferência de calor e de massa, pode ser dividido em três períodos (Figura 1) [3].

A curva (a) representa a diminuição do teor de água do produto durante a secagem, conteúdo de umidade do produto em base seca $(X)$, em relação à evolução do tempo de secagem (t), isto é, é a curva obtida pesando o produto durante a secagem numa determinada condição de secagem.

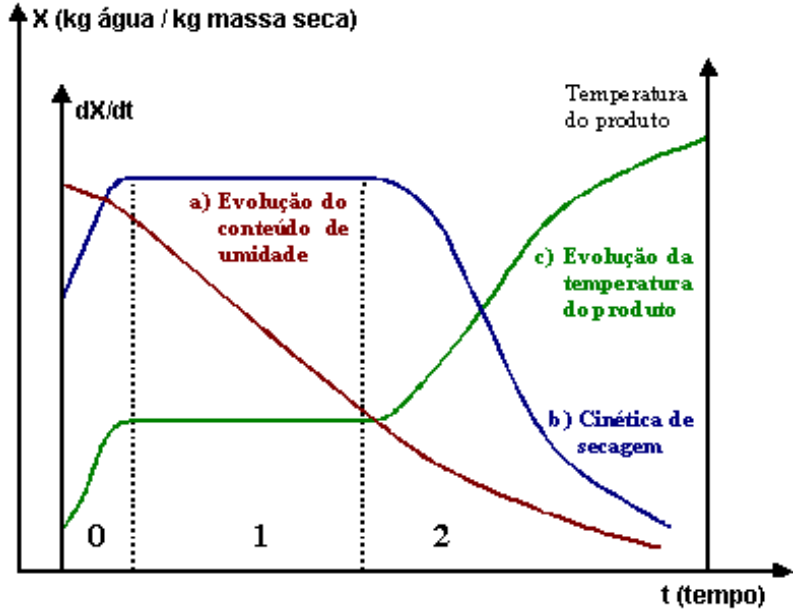

FIGURA 1. Curvas típicas de secagem.

A curva (b) representa a velocidade (taxa) de secagem do produto, variação do conteúdo de umidade do produto por tempo, dX/dt em relação à evolução do tempo (t), isto é, é a curva obtida diferenciando a curva (a).

A curva (c) representa a variação da temperatura do produto durante a secagem (variação da temperatura do produto $(T)$ em relação à evolução do tempo $t$ ), isto é, é a curva obtida medindo a temperatura do produto durante a secagem.

\section{Analisando os períodos:}

O primeiro período representa o início da secagem. Nesse período ocorre uma elevação gradual da temperatura do produto e da pressão de vapor de água. Essas elevações têm prosseguimento até o ponto em que a transferência de calor seja equivalente à transferência de massa (água).

O segundo período caracteriza-se pela taxa constante de secagem. A água evaporada é a água livre. $\mathrm{A}$ transferência de massa e de calor é equivalente e, portanto, a velocidade de secagem é constante. Enquanto houver quantidade de água na superfície do produto suficiente para acompanhar a evaporação, a taxa de secagem será constante.

No terceiro período, a taxa de secagem é decrescente. A quantidade de água presente na superfície do produto é menor, reduzindo-se, portanto, a transferência de massa. A transferência de calor não é compensada pela transferência de massa; o fator limitante nessa fase é a redução da migração de umidade do interior para a superfície do produto. A temperatura do produto aumenta, atingindo a temperatura do ar de secagem. Quando o produto atinge o ponto de umidade de equilíbrio em relação ao ar de secagem, o processo é encerrado.

O terceiro período é quase sempre o único observado para a secagem de produtos agrícolas e alimentícios. A complexidade dos fenômenos, colocados em jogo durante a secagem, conduz os pesquisadores a proporem numerosas teorias e múltiplas fórmulas 
empíricas para predizer a taxa de secagem [3]: Teoria difusional; Teoria capilar; Teoria de Luikov; Teoria de Philip \& de Vries; Teoria de Krisher - Berger \& Pei; Teoria da condensação - evaporação.

As duas primeiras teorias são básicas e fundamentam as outras teorias. A partir dessas teorias teremos os coeficientes de transferência resultantes.

A teoria difusional se apoia exclusivamente sobre a lei de Fick, que expressa que o fluxo de massa por unidade de área é proporcional ao gradiente de concentração de água. Utilizando a lei de Fick, na equação de balanço de massa de água no interior do produto, vem:

$$
\frac{\partial \mathrm{X}}{\partial \mathrm{t}}=\nabla \cdot\left(\mathrm{D}_{\mathrm{ef}} \cdot \nabla \mathrm{X}\right)
$$

Esta forma de Fick é simplificada, já que ela despreza a interdifusão, mas esta hipótese é justificada, uma vez que a água migra dentro de uma matriz fixa.

Independentemente dos trabalhos sobre secagem, CRANK [8] calculou um grande número de soluções da equação de difusão para condições iniciais e de contorno variadas. Entretanto, estas soluções se aplicam aos sólidos de formas geométricas simples (corpos semiinfinitos; placas, cilindros e esferas) e quando a difusividade é constante ou varia linearmente ou exponencialmente com a concentração de água. Para o caso de secagem em sistemas de coordenadas cartesianas, com direção unidirecional em uma placa de espessura $2 \mathrm{~L}$ :

$$
\frac{\partial X}{\partial t}=\frac{\partial}{\partial z}\left(D_{\text {ef }} \frac{\partial X}{\partial z}\right)
$$

A equação 2 com as seguintes condições inicial e de contorno:

Umidade inicial uniforme:

$$
X(z, t)=X(z, 0)=X_{0}
$$

Umidade máxima no centro:

$$
\left.\frac{\partial \mathrm{X}}{\partial \mathrm{z}}\right|_{\mathrm{Z}=0}=0
$$

Umidade constante na superfície: $X(z, t)=X(L, t)=X_{e q}$ E aplicando:

$$
\bar{X}=\frac{1}{L} \cdot \int_{0}^{\mathrm{L}} \mathrm{X}(\mathrm{z}, \mathrm{t}) \mathrm{dz}
$$

\section{Torna-se:}

$\mathrm{Y}=\frac{\bar{X}-\mathrm{X}_{\mathrm{eq}}}{\mathrm{X}_{\mathrm{o}}-\mathrm{X}_{\mathrm{eq}}}=\frac{8}{\pi^{2}} \cdot \sum_{\mathrm{i}=0}^{\infty} \frac{1}{(2 \mathrm{i}+1)^{2}} \exp \left[-(2 \mathrm{i}+1)^{2} \cdot \pi^{2} \cdot \mathrm{D}_{\mathrm{ef}} \cdot \frac{\mathrm{t}}{4 \mathrm{~L}^{2}}\right]$

Onde:

$D_{\text {ef }}$ - Difusividade efetiva $\left(\mathrm{m}^{2} / \mathrm{s}\right) ; \mathrm{Y}$ - conteúdo adimensional de umidade (adimensional); $\bar{X}$ - conteú- do médio de umidade $\left(\mathrm{kg}_{\text {água }} / \mathrm{kg}_{\text {massa seca }}\right) ; X_{\text {eq }}$ - conteúdo de umidade de equilíbrio $\left(\mathrm{kg}_{\text {água }} / \mathrm{kg}_{\text {massa seca }}\right) ; X_{o}-$ conteúdo de umidade no instante inicial $\left(\mathrm{kg}_{\text {água }} / \mathrm{kg}_{\text {massa seca }}\right)$; $\mathrm{i}$ - número de termos na série; $\mathrm{t}$ - tempo (s); $\mathrm{L}$ - comprimento característico, semi-espessura da amostra $(\mathrm{m})$; $z$ - direção da transferência (m).

Apesar de inúmeros esforços no sentido de se obter um modelo teórico para o processo de secagem, os dados experimentais ainda têm um papel importante no estudo da desidratação de alimentos [12].

Para a escolha de um processo ideal de secagem deve-se analisar vários fatores como: propriedades organolépticas (sabor e aroma), tempo e energia gasta. O tempo de processo, ou seja, a velocidade de troca de calor entre a matéria-prima e o ar pode ser analisado através da difusividade efetiva nas diversas temperaturas de processo.

A dependência da difusividade com a temperatura é expressa pela energia de ativação baseada em uma equação do tipo Arrhenius:

$\ln \left(\mathrm{D}_{\mathrm{ef}}\right)=\ln \left(\mathrm{D}_{0}\right)-\frac{\mathrm{Ea}}{\mathrm{R} \cdot \mathrm{T}}$

Onde:

$D_{\text {ef }}$ - difusividade efetiva $\left(\mathrm{m}^{2} / \mathrm{s}\right) ; D_{0}-$ Fator de Arrhenius $\left(\mathrm{m}^{2} / \mathrm{s}\right)$; Ea - energia de ativação $(\mathrm{J} / \mathrm{mol}) ; \mathrm{R}-$ constante universal dos gases $(8,1314 \mathrm{~J} / \mathrm{mol} \mathrm{K}) ; \mathrm{T}-$ temperatura absoluta $(\mathrm{K})$.

\section{2 - MATERIAL E MÉTODOS}

\section{1 - Material}

Para a secagem da pêra foram utilizados os seguintes materiais: secador vertical convectivo (Figura 2) [4]; pêra variedade Bartlett; anemômetro digital; balança digital semi-analítica; termo-higrógrafo e estufa a vácuo.

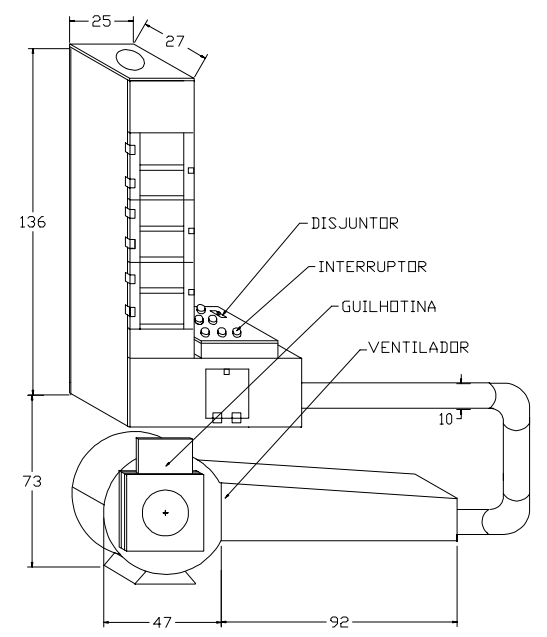

FIGURA 2. Secador vertical convectivo (medidas em $\mathrm{cm}$ ). 


\section{2 - Metodologia}

\subsection{1 - Secagem}

$\mathrm{Na}$ realização do experimento de secagem foi necessário o controle do fluxo de ar e da temperatura dentro do secador. A temperatura era mantida constante através da regulagem do controlador digital do secador. Durante a secagem, as fatias de pêra foram pesadas periodicamente para levantamento das curvas de secagem.

\subsection{2 - Determinação da massa seca da pêra}

Para determinação da massa seca da pêra foram retiradas amostras em triplicata de $5 \mathrm{~g}$ do produto após o processo de secagem. Estas amostras foram colocadas em cadinhos de alumínio dentro de uma estufa a vácuo a $70^{\circ} \mathrm{C}$ por 24 horas, conforme a metodologia descrita pela AOAC [1].

\subsection{3 - Determinação da difusividade efetiva}

Conhecendo a umidade relativa e a temperatura do ar ambiente pode-se encontrar sua atividade de água na respectiva temperatura de secagem com o auxílio da carta psicrométrica. Com este valor de atividade de água, encontra-se o valor da umidade de equilíbrio através do modelo de isoterma de dessorção de PELEG [16]:

$\mathrm{X}_{\mathrm{eq}}=\mathrm{k}_{1} \cdot \mathrm{a}_{\mathrm{w}}^{\mathrm{n}_{1}}+\mathrm{k}_{2} \cdot \mathrm{a}_{\mathrm{w}}^{\mathrm{n}_{2}}$

Onde:

$a_{w}$ - atividade de água; $k_{1}, k_{2}, n_{1}$ e $n_{2}$ - parâmetros do modelo de Peleg.

Determinada a umidade de equilíbrio da pêra nas condições de secagem, calcula-se o número adimensional de umidade (umidade instantânea - umidade de equilíbrio / umidade inicial - umidade de equilíbrio). Os valores dos adimensionais para cada tempo durante a secagem foram ajustados utilizando a Segunda Lei de Fick. utilizando-se o STATISTICA [17], variando os termos da série. O resultado que apresentar menor erro relativo será utilizado para cálculo da difusividade.

\section{3 - RESULTADOS E DISCUSSÃO}

Os parâmetros obtidos utilizando o modelo de Peleg para dessoração da pêra estão indicados na Tabela 1 [15].

TABELA 1. Parâmetros do modelo de Peleg para a pêra.

\begin{tabular}{cccc}
\hline \multirow{2}{*}{ Parâmetros } & \multicolumn{3}{c}{ Temperaturas $\left({ }^{\circ} \mathbf{C}\right)$} \\
\cline { 2 - 4 } & $\mathbf{5 0}$ & $\mathbf{6 0}$ & $\mathbf{7 0}$ \\
\hline $\mathrm{k}_{1}$ & 0,296 & 0,263 & 0,264 \\
$\mathrm{k}_{2}$ & 13,408 & 31,504 & 140,245 \\
$\mathrm{n}_{1}$ & 0,353 & 0,425 & 0,814 \\
$\mathrm{n}_{2}$ & 14,694 & 18,122 & 24,854 \\
\hline
\end{tabular}

As Figuras 3, 4 e 5, a seguir, mostram o adimensional de secagem versus o tempo para as três temperaturas e três velocidades do ar de secagem:

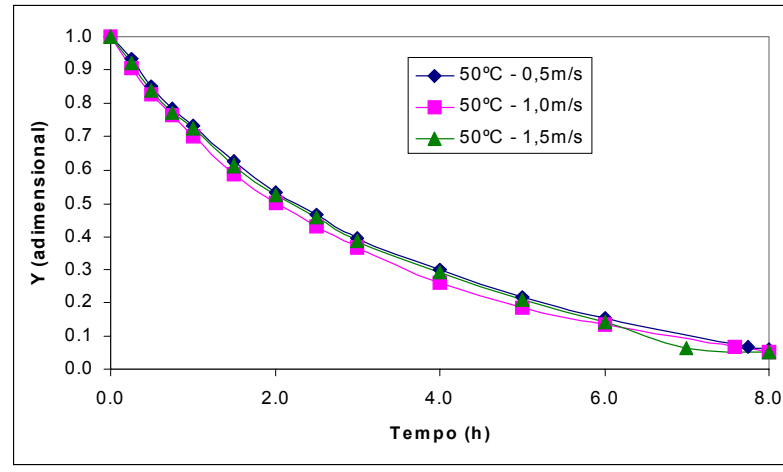

FIGURA 3. Curva de secagem para a temperatura de $50^{\circ} \mathrm{C}$.

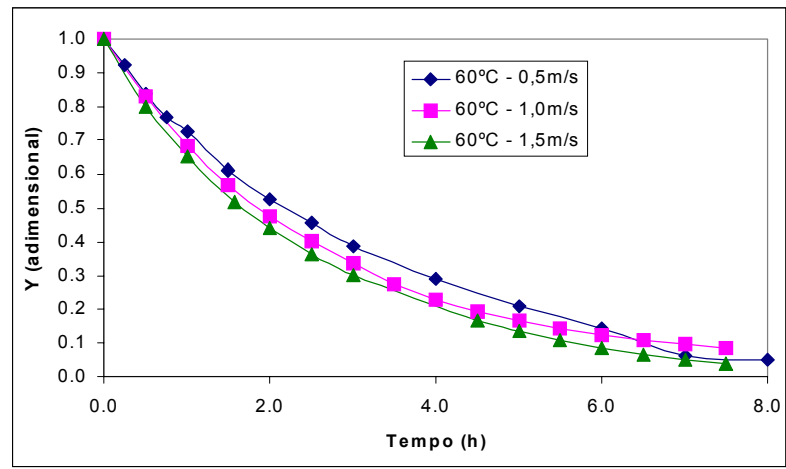

FIGURA 4. Curva de secagem para a temperatura de $60^{\circ} \mathrm{C}$.

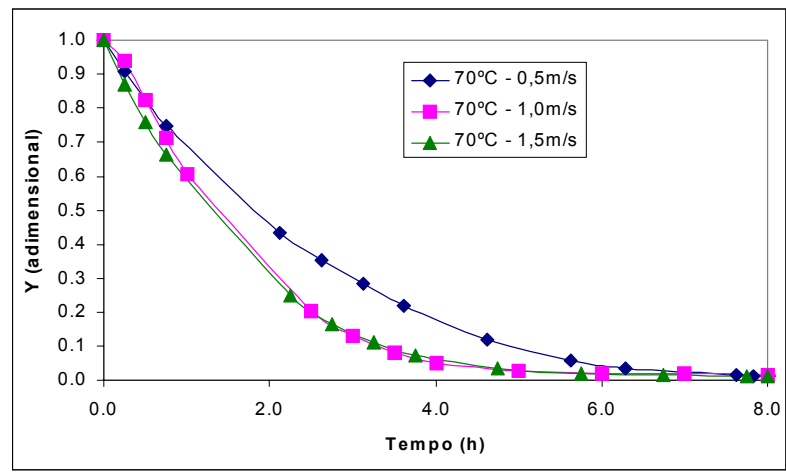

FIGURA 5. Curva de secagem para a temperatura de $70^{\circ} \mathrm{C}$.

Para o cálculo da difusividade foi utilizada a Equação de Fick com 1, 3, 5, 10 e 15 termos. A espessura média das fatias de pêra utilizadas foi de $1,0 \mathrm{~cm}$. Os resultados de difusividade para cada condição de secagem estão mostrados na Tabela 2.

Como pode ser observado, não houve diferenças no valor da difusividade efetiva com o uso de 3 termos ou mais. Mas, o menor erro relativo foi observado com a utilização de 15 termos da equação 4. A partir destes valores, a energia de ativação foi calculada segundo a equação tipo Arrenhius (Tabela 3). 
TABELA 2. Difusividade efetiva para cada condição de secagem.

\begin{tabular}{ccccccc}
\hline \multirow{2}{*}{$\mathbf{T}\left({ }^{\circ} \mathbf{C}\right)$} & \multirow{V}{*}{$(\mathbf{m} / \mathbf{s})$} & \multicolumn{5}{c}{ Difusividade efetiva $\left(\mathbf{m}^{2} / \mathbf{s} \mathbf{x} \mathbf{1 0}^{-\mathbf{9}}\right)$} \\
\cline { 3 - 7 } & & $\mathbf{1}$ Termo & $\mathbf{3}$ Termos & $\mathbf{5}$ Termos & $\mathbf{1 0}$ Termos & $\mathbf{1 5}$ Termos \\
\hline \multirow{3}{*}{50} & 0,5 & 6,461 & 6,450 & 6,450 & 6,450 & 6,450 \\
& 1,0 & 7,128 & 7,122 & 7,122 & 7,122 & 7,122 \\
& 1,5 & 6,728 & 6,719 & 6,719 & 6,719 & 6,719 \\
\hline \multirow{2}{*}{60} & 0,5 & 5,567 & 5,564 & 5,564 & 5,564 & 5,564 \\
& 1,0 & 8,042 & 8,042 & 8,042 & 8,042 & 8,042 \\
& 1,5 & 9,083 & 9,081 & 9,081 & 9,081 & 9,081 \\
\hline \multirow{2}{*}{70} & 0,5 & 9,367 & 9,356 & 9,356 & 9,356 & 9,356 \\
& 1,0 & 12,617 & 12,600 & 12,600 & 12,600 & 12,600 \\
& 1,5 & 13,717 & 13,706 & 13,703 & 13,703 & 13,703 \\
\hline
\end{tabular}

TABELA 3. Energia de ativação para a pêra.

\begin{tabular}{|c|c|c|c|}
\hline $\mathrm{v}(\mathrm{m} / \mathrm{s})$ & $\mathbf{T}(\mathrm{K})$ & $D_{\text {ef }}\left(\mathrm{m}^{2} / \mathrm{s}\right)$ & Ea $(\mathrm{J} / \mathrm{mol})$ \\
\hline \multirow{3}{*}{0,5} & 323,15 & $6,450 \times 10^{-9}$ & \multirow{3}{*}{$16.460,3$} \\
\hline & 333,15 & $5,564 \times 10^{-9}$ & \\
\hline & 343,15 & $9,356 \times 10^{-9}$ & \\
\hline \multirow{3}{*}{1,0} & 323,15 & $7,122 \times 10^{-9}$ & \multirow{3}{*}{$25.564,0$} \\
\hline & 333,15 & $8,042 \times 10^{-9}$ & \\
\hline & 343,15 & $1,260 \times 10^{-8}$ & \\
\hline \multirow{3}{*}{1,5} & 323,15 & $6,719 \times 10^{-9}$ & \multirow{3}{*}{$32.067,2$} \\
\hline & 333,15 & $9,081 \times 10^{-9}$ & \\
\hline & 343,15 & $1,370 \times 10^{-8}$ & \\
\hline
\end{tabular}

A energia de ativação mostrada na Tabela 3 exibe uma magnitude perto dos valores encontrados na literatura propostos para materiais biológicos: sementes de trigo, de 54 a $70,2 \mathrm{~kJ} / \mathrm{mol}$ [2]; gel de amido, de 18,8 a $50 \mathrm{~kJ} / \mathrm{mol}$ [9]; soja, de 28,8 a $30 \mathrm{~kJ} / \mathrm{mol}$ [11]; cebolinha, de 29,05 a $42,05 \mathrm{~kJ} / \mathrm{mol}$ [14]; champinhon em conserva, de 23,89 a $31,45 \mathrm{~kJ} / \mathrm{mol}$ [5].

\section{4 - CONCLUSÕES}

Os valores da difusividade aumentaram com o aumento da temperatura do ar de secagem (estes valores variam de $5,564 \times 10^{-9}$ até $1,370 \times 10^{-8} \mathrm{~m}^{2} / \mathrm{s}$ ), mostrando a diminuição das resistências internas de secagem com o aumento da temperatura.

A difusividade efetiva da pêra aumenta com o aumento da velocidade do ar, sendo que este aumento é mais acentuado conforme aumenta a temperatura. Este comportamento pode ser explicado pela diminuição da resistência externa com o aumento do coeficiente convectivo em função do aumento da velocidade e da temperatura do ar de secagem. Este aumento do coeficiente convectivo causa aumento na temperatura do material, diminuindo a resistência interna em função do aumento da temperatura. O aumento dos valores de energia de ativação com o aumento da velocidade do ar $(16.460,3 \mathrm{~J} / \mathrm{mol}$ para a velocidade do ar de $0,5 \mathrm{~m} / \mathrm{s}$, $25.564,0 \mathrm{~J} / \mathrm{mol}$ para a velocidade do ar de $1,0 \mathrm{~m} / \mathrm{s}$ e $32.067,2 \mathrm{~J} / \mathrm{mol}$ para a velocidade de $1,5 \mathrm{~m} / \mathrm{s}$ ) reforça esta relação das resistências interna versus externa.

\section{5 - REFERÊNCIAS BIBLIOGRÁFICAS}

[1] ASSOCIATION OF OFFICIAL ANALYTICAL CHEMISTS AOAC. Official Methods of Analysis: 930.04, Moisture Content in Plants, 1990, v. 1.

[2] BECKER, H. A., SALLANS, H. R. A study of internal moisture movement in the drying of the wheat kernel. Cereal Chemistry. St. Paul: Amer Assoc Cereal Chemists, v. 32, n. 3, p. 212-226, 1955.

[3] BROD, F.P.R., ALONSO, L.F.T., PARK, K.J. Secagem de produtos agrícolas. XI SEMEAGRI - Semana de Engenharia Agrícola da Unicamp. Campinas: Agrológica - Empresa Júnior de Eng. Agrícola. 1999, 122 p.

[4] BROD, F.P.R., SILVA, J.E.A.R., PARK, K.J. Construção de secador: parte 1 - secador vertical convectivo. Engenharia Rural. Piracicaba: ESALQ/USP, v. 8, n. 1, p. 112-120, 1997.

[5] BRÒVIA i PIJUAN, M.N., BROD, F.P.R., PARK, K.J. Estudio de secado de champiñón en conserva (Agaricus bisporus) utilizando un secador vertical. Alimentaria: revista de tecnologia e higiene de los alimentos. Madri-Espanha: Auditores y Técnicos, v. 286, p. 119-122, 1997.

[6] CAMPO-DALL'ORTO, F.A., OJIMA, M., BARBOSA, W., RIGITANO, O., MARTINS, F.P., CASTRO, J.L., SANTOS, R.R., SABINO, J. C. Variedades de pêra para o Estado de São Paulo. Campinas: Instituto Agronômico de Campinas, 1996. 33p.

[7] COPLEY, M.J., Van ARDSEL, W.B. Food dehydration. Westport, Connecticut. 1964, v. 2. p. 467-507.

[8] CRANK, J. The mathematics of diffusion. 2. ed. Oxford: Clarendon Press, 1975. 414 p.

[9] FISH, B.P. Diffusion and thermodynamics of water in potato starch gel. In: Fundamental aspects of the dehydration of foodstuffs. [s.I.]: Soc. Chem. In., p. 143-157, 1975.

[10] GUIÃO, E.P. A cultura da pereira. São Paulo: ABC do Lavrador Prático, 2. ed. 1964, 31p.

[11] KITIC, D., VIOLLAZ, P.E. Comparison of drying kinetic of soybeans in thin layer and fluidized beds. Journal of Food Technology. Oxford, Blackwell Science Ltd, v. 19, n. 4, p. 399-408, 1984.

[12] MAZZA, G., LEMAGUER, M. Dehydration of onion: some theoretical and practical considerations. Journal of Food Technology, Oxford: Blackwell Science Ltd, v. 15, n. 2, p. 181-194, 1980.

[13] McBEAN, D. Improved dried pears. CSIRO Fd. Preserv. Q, v. 29, n. 3, 1959, $4 p$.

[14] PARK, K.J., BROD, F.P.R., SILVA, J.E.A.R. Estudo comparativo de secagem de cebolinha (Allium sp. cv. Galega) utilizando secadores vertical e horizontal. Revista Ciência e Tecnologia de Alimentos. Campinas/SP: SBCTA, v. 16, n. 2, p. 143-145, 1996.

[15] PARK, K.J., YADO, M.K.M., BROD, F.P.R. Isotermas de dessorção para a pêra bartlett (Pyrus sp.). Engenharia Rural. Piracicaba: ESALQ/USP, 2000 (submetido).

[16] PELEG, M. Assessment of a semi-empirical four parameter general model for sigmoid moisture sorption isotherms. Journal of Food Processing Engineering, ConnecticutUSA: Food \& Nutrition Press Inc., v. 16, n. 1, p. 21-37, 1993.

[17] STATISTICA for Windows 5.0. Computer program manual. Tulsa, OK: StatSoft, Inc., 1995. 